\title{
Analysis of hidden safety hazards and treatment suggestions when the floating roof of oil storage tanks falls to the bottom
}

\author{
Jiahao Yang ${ }^{1}$, Fan Zhou ${ }^{2}$,Weixing Wu ${ }^{3}$, Jun Zhang ${ }^{4}$, Shaoqiang Chen ${ }^{5}$ and Genmin Zhu* \\ ${ }^{1}$ School of Petrochemical and Environmental Sciences, Zhejiang Ocean University, Zhoushan, Zhejiang, 316022, China \\ ${ }^{2}$ School of Petrochemical and Environmental Sciences, Zhejiang Ocean University, Zhoushan, Zhejiang, 316022, China \\ ${ }^{3}$ School of Petrochemical and Environmental Sciences, Zhejiang Ocean University, Zhoushan, Zhejiang, 316022, China \\ ${ }^{4}$ Bureau of Emergency Management of Zhoushan, Zhoushan, Zhejiang, 316022, China \\ ${ }^{5}$ Bureau of Emergency Management of Zhoushan, Zhoushan, Zhejiang, 316022, China \\ *School of Petrochemical and Environmental Sciences, Zhejiang Ocean University, Zhoushan, Zhejiang, 316022, China
}

\begin{abstract}
In the actual production and operation of enterprises, it is sometimes inevitable that the floating roof will fall to the bottom. This paper calculates the explosion limit of the mixture of oil gas under the floating roof, and confirms that the concentration of oil gas will be within the explosion limit under certain circumstances. Through the monitoring and analysis of the oil-gas mixing space below the floating roof, corresponding control measures are proposed to deal with the potential safety hazards of the floating plate falling to the bottom.
\end{abstract}

\section{Introduction}

In the petrochemical industry, safety has always been a topic that cannot be ignored[1-4]. With the increase in energy demand, the petrochemical industry's storage of flammable and explosive products has become larger and larger, and the capacity of a large oil depot can reach several million cubic meters. According to the analysis of 242 industrial equipment storage tank accidents in the past 40 years, $74 \%$ of accidents occurred in refineries, oil terminals or oil storage depots, and fires and explosions accounted for $85 \%$ of accidents[5].Because the stored light crude oil is flammable, explosive and volatile, fire and explosion accidents are one of the main reasons for the high risk of large oil depots[6].Since the Chicago Bridge Iron Company (CB\&I) first demonstration in 1923, floating roof storage tanks have been the most widely used storage method for volatile petroleum products[7]. The floating roof tank uses a floating roof that floats on the liquid surface of the oil tank as the oil rises and falls. The use of this top cover to cover the liquid surface can effectively isolate the oil from the air, reduce the evaporation loss of the oil, and reduce the risk of fire and explosion and material loss[8].

In the daily management of floating roof storage tanks, there are also many hidden safety hazards. A major feature of floating roof storage tanks is that the floating plate can move up and down freely with the oil level, so that there is no oil gas mixing space above the oil level[8]. When it reaches its low level, the column that can be supported on the floating plate itself will not continue to fall, but at this time when the oil level drops again, there will be an oilgas mixing space between the floating plate and the oil level. If the supervision measures are not taken properly, when the concentration of oil gas is within the explosive limit, the storage tank will be in danger of explosion.

At present, most commercial oil depots will almost inevitably face the problem of floating roof falling to the bottom during actual operation. This is mainly reflected in the need to empty the tank and flush the medium when the entire tank needs to be replaced due to business requirements. In the process of emptying, the floating plate drops to the bottom, and the liquid level continues to drop, and the above-mentioned oil-gas mixing space exists. This part of the oil-gas mixing space currently has no mature monitoring and control methods, and there are potential safety hazards.

In this paper, the Japan New Universe XP-3140 combustible gas detector is used to detect the oil gas concentration in the oil-gas mixing space after the floating roof falls in real time, and the Fuli GC9720 gas chromatograph is used to analyze the oil gas samples in the oil-gas mixing space to calculate the explosion limit. Afterwards, a 6-day fixed-point and regular monitoring of the external wind, the concentration of oil gas in the oilgas mixing space, and the temperature were carried out, and the law of the change of the oil gas concentration was analyzed. Finally, the safety management and control measures for the bottom of the floating plate were proposed.

${ }^{*}$ Corresponding author's e-mail: S19082000011@zjou.edu.cn 


\section{Explosion limit analysis}

\section{1 oil gas sampling}

Sampling the oil gas in the oil-gas mixing space after the $50,000 \mathrm{~m}^{3}$ crude oil storage tank TK 107 floating roof of a commercial oil depot in Zhoushan, Zhejiang Province fell to the bottom, the oil gas concentration was $13.4 \%$ and $16 \%$ detected by the Japanese New Universe XP-3140 portable gas detector, and recorded as TK 107-13.4\% and TK 107-16\%, combined with Fuli GC 9720 gas chromatograph for component analysis.

\subsection{Gas chromatograph working conditions and standard gas analysis}

Fuli GC 9720 gas chromatograph working conditions: oven temperature $100^{\circ} \mathrm{C}$, limit temperature $400^{\circ} \mathrm{C}$, injection port temperature $120^{\circ} \mathrm{C}$, split ratio $40: 1$, FID detector temperature $180^{\circ} \mathrm{C}$, hydrogen flow rate $30 \mathrm{ml} / \mathrm{min}$, air flow rate $300 \mathrm{ml} / \mathrm{min}$, the nitrogen flow rate is $30 \mathrm{ml} / \mathrm{min}$.

The standard gas was purchased from the Chinese Academy of Metrology, and its composition and gas chromatogram are as Figure 1.

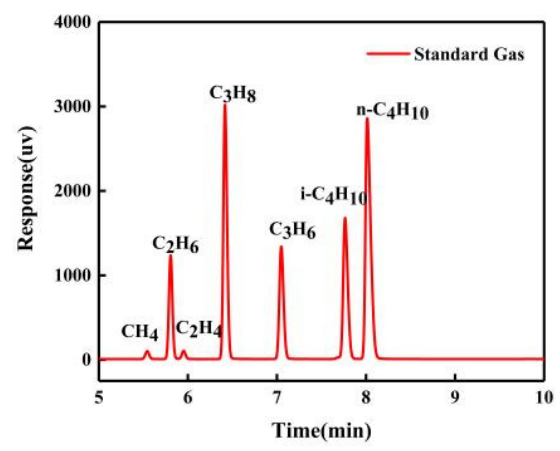

Figure 1. Standard Gas chromatograms

\subsection{Calculation method of explosion limit}

After the floating roof falls to the bottom, the automatic vent valve opens automatically, and the oil-gas mixing space is directly connected to the atmosphere, so the explosion limit of this mixture is calculated by the explosion limit calculation method of the mixed gas containing oxygen. It is necessary to deduct the oxygen content and the nitrogen content obtained according to the oxygen-nitrogen ratio of the air, and readjust the volume fraction of each component in the mixed gas for calculation.

Because the oil-gas mixing space below the floating roof is directly connected to the atmosphere through an automatic vent valve, in this experiment, the ratio of oxygen to nitrogen except for the oil gas concentration is distributed according to the ratio of oxygen and nitrogen in the air. After removing this part of the oxygen and nitrogen ratio, the Le Chatelier rule is used to mix The explosion limit of the gas is calculated.

\subsection{Sample detection analysis calculation}

\subsubsection{TK 107-13.4\% composition and explosion limit calculation}

First, use Fuli GC 9720 gas chromatograph to detect the sample TK $107-13.4 \%$, and the gas chromatogram is as Figure2.

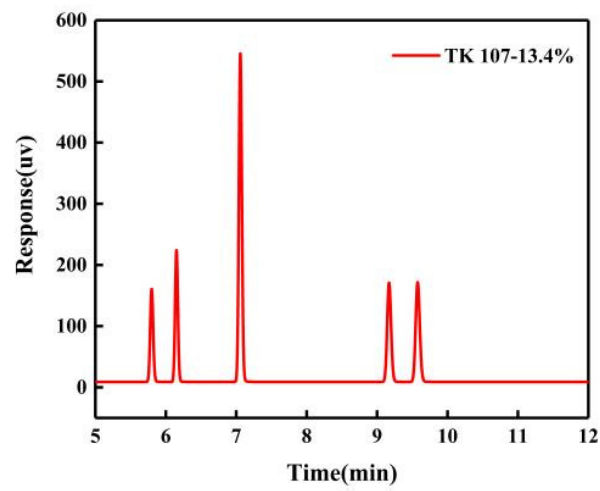

Figure 2.TK 107-13.4\% gas chromatogram

Compare with the standard gas to determine the composition and corresponding concentration as shown in table 1 .

Table 1. TK 107-13.4\% oil gas composition and concentration

\begin{tabular}{|c|c|}
\hline oil gas composition & Concentration(\%) \\
\hline $\mathrm{C}_{2} \mathrm{H}_{6}$ & 1.53 \\
\hline $\mathrm{C}_{2} \mathrm{H}_{4}$ & 2.03 \\
\hline $\mathrm{C}_{3} \mathrm{H}_{6}$ & 5.47 \\
\hline $\mathrm{i}-\mathrm{C}_{4} \mathrm{H}_{10}$ & 2.12 \\
\hline $\mathrm{n}-\mathrm{C}_{4} \mathrm{H}_{10}$ & 2.26 \\
\hline
\end{tabular}

Using Le Chatelier's law to calculate the explosion limit of the mixed gas, the lower explosion limit is $14.90 \%$, and the upper explosion limit is $85.47 \%$. The $13.4 \%$ oil gas concentration of this sample is outside the explosion limit range

\subsubsection{TK 107-16\% composition and explosion limit calculation}

First, use Fuli GC 9720 gas chromatograph to detect the sample TK $107-16 \%$, and the gas chromatogram is as Figure3. 


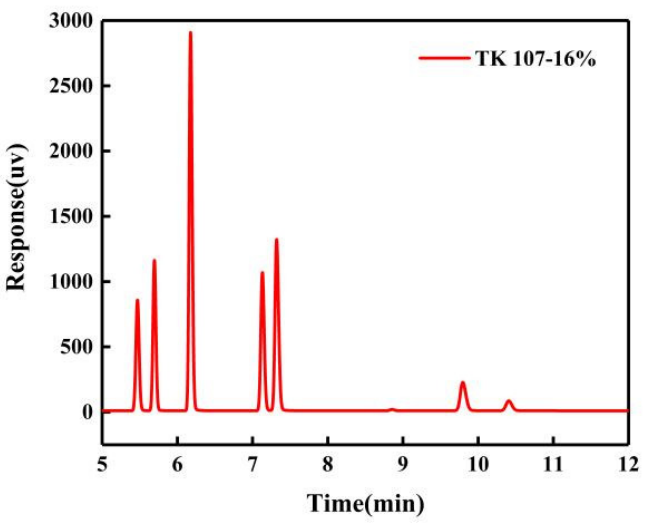

Figure 3.TK 107-16\% gas chromatogram

Compare with the standard gas to determine the composition and corresponding concentration as shown in Table 2.

Table 2. TK 107-16\% oil gas composition and concentration

\begin{tabular}{|c|c|}
\hline oil gas composition & Concentration(\%) \\
\hline $\mathrm{CH}_{4}$ & 1.68 \\
\hline $\mathrm{C}_{2} \mathrm{H}_{6}$ & 2.09 \\
\hline $\mathrm{C}_{3} \mathrm{H}_{8}$ & 5.34 \\
\hline $\mathrm{C}_{3} \mathrm{H}_{6}$ & 2.19 \\
\hline $\mathrm{i}-\mathrm{C}_{4} \mathrm{H}_{10}$ & 3.94 \\
\hline
\end{tabular}

Using Le Chatelier's law to calculate the explosion limit of the mixed gas, the lower explosion limit is $13.54 \%$, and the upper explosion limit is $64.53 \%$. The $16 \%$ oil gas concentration of this sample is within the explosive limit.

\subsection{Security analysis}

From the above explosion limit analysis results, it can be seen that after the floating roof of the external floating roof storage tank falls to the bottom, the oil gas concentration may be lower than the lower explosion limit under the

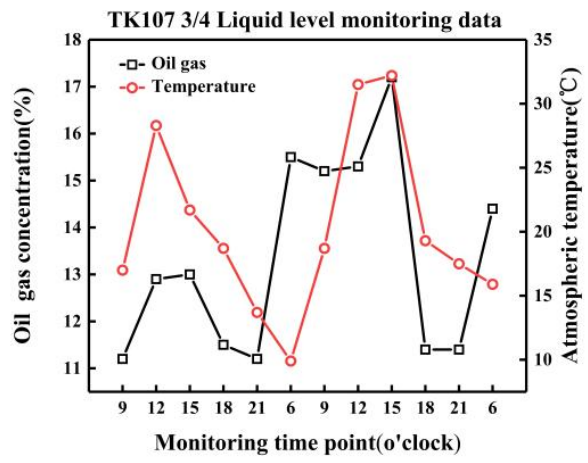

Figure 4. 3/4 liquid level monitoring data condition of low oil gas concentration. As the concentration of oil gas increases, the concentration of oil gas is also within the explosive limit. What is certain is that the concentration of oil gas will also be within the explosive limit range from time to time. This will bring major safety hazards to petrochemical companies, and we must take targeted safety measures to escort safe production.

\section{Conclusions-Safety control measures}

When the floating roof of the external floating roof oil storage tank falls to the bottom, the oil level continues to drop, and there is an oil-gas mixing space below the floating roof and above the oil level. This oil-gas mixing space has the potential to explode and burn. In the normal operation of oil depots, it is inevitable that the floating roof will fall to the bottom, especially for commercial oil depots. So how to control this is particularly important. The control measures mainly start from three aspects. One is to control the concentration of oil gas below the lower explosive limit or not to meet the combustion conditions; the other is to intervene the combustion aid to prevent it from reaching the combustion conditions; the third is to strictly control the ignition source. One of the unavoidable problems is how to control the oil gas concentration in the oil-gas mixing space.

\subsection{Analysis of oil gas concentration changes}

In order to select appropriate measures to control the oil gas concentration in this oil-gas mixing space, the size of the oil-gas mixing space, temperature and wind are set as three influencing factors for the change of oil gas concentration after the floating roof falls to the bottom for data collection.

Based on the vertical height from the bottom of the floating roof to the bottom of the tank, the oil level in the tank reaches $3 / 4,1 / 2$, and $1 / 4$ heights respectively, and each level stays for 48 hours, corresponding to three different levels. The large and small oil-gas mixing space has undergone a 6-day fixed-point timing inspection based on the actual work situation of the enterprise.

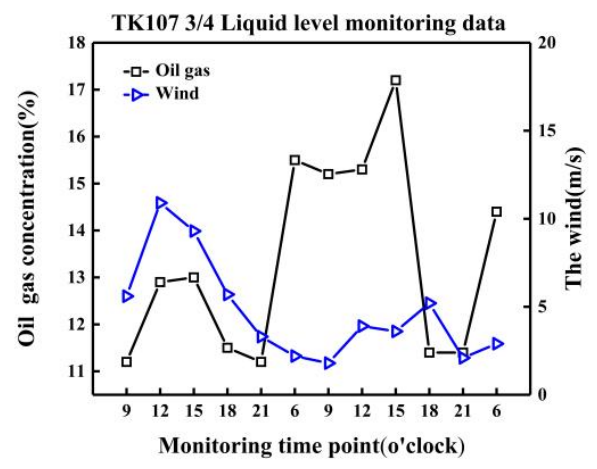

Figure 5 .3/4 liquid level monitoring data 


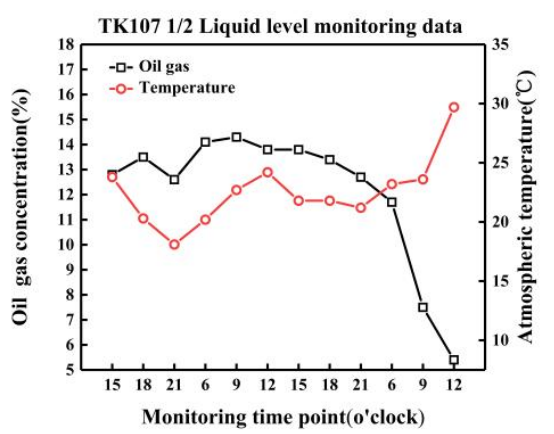

Figure 6.1/2liquid level monitoring data

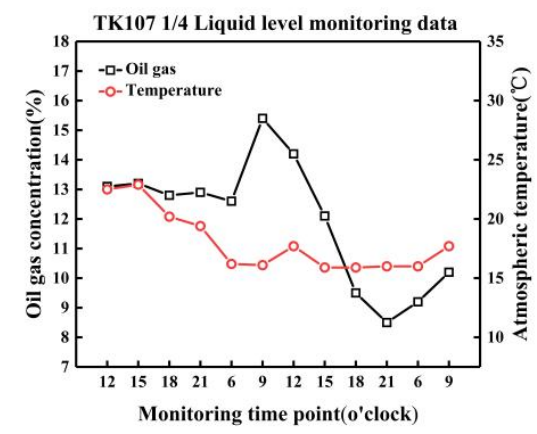

Figure 8 1/4liquid level monitoring data

Comparing Figures 4,6,8 and Figure 5,7,9can analyze the influence of oil-gas mixing space size. It is observed that the time nodes where the temperature and wind speed in each liquid level data are relatively close, the oil gas concentration is also very close, and the fluctuation range of the oil gas concentration is relatively balanced on the whole, except for data points with extremely low oil gas concentration caused by the influence of large wind, The oil gas concentrations shown by the remaining data points are all within the same range.

Comparing Figures 4, 6, and 8, it can be found that the temperature effect is more significant. The change curve of oil gas concentration and the change curve of temperature are very similar in the change trend. Generally speaking, as the temperature increases, the concentration of oil gas rises, while the temperature decreases, and the concentration of oil gas decreases. This is because the change of outside temperature has an important influence on the volatilization of oil. As the temperature rises, the saturated vapor pressure of the light components in the oil will increase, and more light hydrocarbons will have a tendency to evaporate to ensure that the vapor pressure above the oil level and the new saturated vapor pressure reach a new dynamic Balance, so that the concentration of oil gas rises. On the other hand, with the increase of temperature, the resistance of liquid phase migration inside crude oil decreases, and the environmental diffusion speed of volatile molecules increases, which also leads to the increase of oil gas concentration.

Comparing Figures 5, 7, and 9, it can be found that the magnitude of external wind has a significant impact on the changes in oil gas concentration. Since the automatic vent valve above the floating roof is opened after the floating

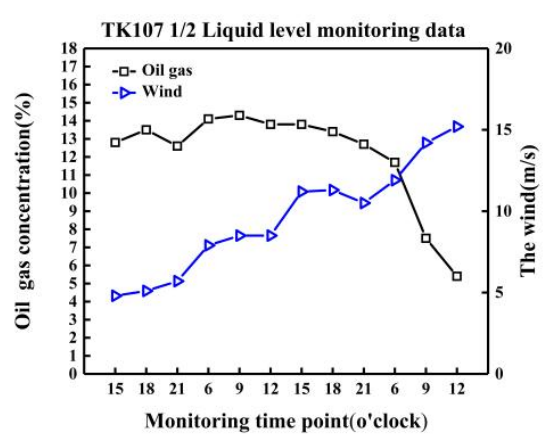

Figure 7.1/2liquid level monitoring data

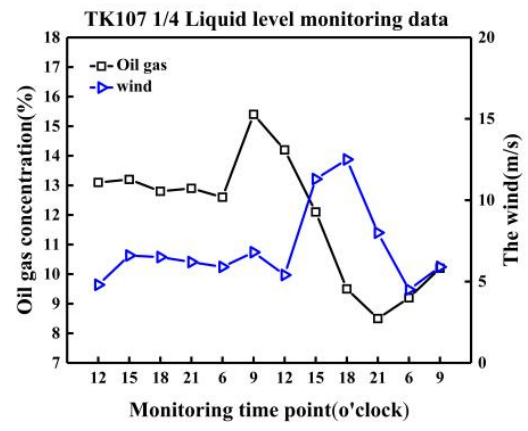

Figure 9 .1/4liquid level monitoring data

roof falls to the bottom, the entire oil-gas mixing space under the floating roof is directly connected to the atmosphere, so the change of external wind will directly affect the oil-gas mixing space under the floating plate. When the wind reaches the strong wind level and the wind speed reaches more than $10 \mathrm{~m} / \mathrm{s}$, the concentration of oil gas drops significantly. When the wind does not reach the strong wind level and the wind speed is below $10 \mathrm{~m} / \mathrm{s}$, the effect of wind on the change of oil gas concentration is not significant.

In summary, to control the concentration of oil gas in the oil-gas mixing space, the control can be started from two points: temperature and wind.

\subsection{Choice of control measures}

\subsubsection{Control oil gas concentration}

When the floating roof falls to the bottom, a combustible gas detection probe can be set to monitor the oil gas in real time. Once the concentration is too high, control measures must be taken. The control measures start with temperature and wind.First, try to avoid the floating-roof from falling to the bottom in high temperature weather, no wind or weak wind, and the safety of the bottom falling operation in low temperature and strong wind is higher. The second is to spray and cool the floating roof and tank wall, so that the oil gas in the internal oil-gas mixing space can be condensed and the oil gas concentration can be reduced to a safe range. 


\subsubsection{Control combustion-supporting agent oxygen}

As the floating roof falls to the bottom, the automatic vent valve on the floating plate is automatically opened. The oil gas below the floating roof are communicated with the atmosphere. The volatilization of oil increases and a strong gas exchange occurs with the outside. A large amount of air flows into the oil-gas mixing space, which includes The combustion-supporting agent oxygen. By controlling the concentration of oxygen so that it cannot reach the combustion conditions, combustion can be prevented. The oxygen content detection probe and inert gas replacement system can be installed after the floating roof falls to the bottom to monitor the oxygen concentration in real time. When the oxygen concentration reaches the combustion conditions, inert gas (such as nitrogen) is flushed into the oil-gas mixing space to reduce the oxygen concentration, The purpose of preventing the combustion of oil gas.

\subsubsection{Strictly control the ignition source}

If both combustibles and combustion-supporting agent oxygen reach the conditions of combustion and explosion, the source of ignition is the last insurance. In terms of fire source management and control, all safety systems of the enterprise should be strictly implemented, and all fire sources should be closely controlled. In particular, measures should be taken to reduce static electricity accumulation and accelerate static electricity dissipation in accordance with enterprise operating procedures.

\section{Acknowledgement}

The authors gratefully acknowledge the support from Zhoushan Science and Technology Program of Zhejiang Province (2017C12029) and basic public welfare research plan of Zhejiang Province(LGF19B070004).

\section{References}

1. Du Z, Mao Y, Lu M. Design and implementation of safety management system for oil depot based on Internet of Things[C]//2012 IEEE International Conference on Green Computing and Communications. IEEE, 2012: 249-252.

2. Lin S, Yi P, Shuangchun Y. The cause of fire and preventive measures in oil $\operatorname{depot}[\mathrm{J}]$. Int. J. Eng. Res. Dev, 2012, 4(11): 55-57.

3. Zhang F, Jiang H, Zhang C. Study of charging nitrogen to external floating roof tank to prevent rimseal fires from lightning $[\mathrm{J}]$. Procedia engineering, 2014, 71: 124-129.

4. Moshashaei P, Alizadeh S S, Khazini L, et al. Investigate the causes of fires and explosions at external floating roof tanks: A comprehensive literature review $[\mathrm{J}]$. Journal of Failure Analysis and Prevention, 2017, 17(5): 1044-1052.

5. Chang J I, Lin C C. A study of storage tank accidents $[\mathrm{J}]$. Journal of loss prevention in the process industries, 2006, 19(1): 51-59.

6. Xu-qingFP L, Quan-Zhen L, Hong G. Study of fire fighting system to extinguish full surface fire of large scale floating roof tanks[J]. Procedia Engineering, 2011, 11: 189-195.

7. Gallagher T A, Desjardins C R. Floating-Roof Tanks: Design and Operation in the Petroleum Industry[C]//International Pipeline Conference. American Society of Mechanical Engineers, 2000, 40245: V001T02A007.

8. Kuan S Y. Design, construction and operation of the floating roof tank[J]. 2009. 